measurement. As cost data were not normally distributed, standard errors (SEs), $95 \%$ confidence intervals (Cls) and $P$ values were estimated by bootstrap resampling (10,000 samples).

Results: Data were available for 95 PsA patients (female: $n=43$ ). Mean HAQ-DI score was 0.81 (SE 0.08); mean age at HAQ-DI measurement was 58.6 (SE 1.04). Mean total annual healthcare costs, excluding medication costs, were $£ 1,588$ (SE 172.3). Regression modelling indicated that a 1-point increase in HAQ-DI score was associated with an increase in total costs, excluding medications, of $£ 547.49$ (SE 222.7; 95\% Cl 191.7-1,103.8; $P=0.004$ ) (Table). Subgroup analyses suggested trends for higher cost increases within the lower HAQ-DI cutoff subgroup (HAQ-DI 0-1) and for those with greatest disease duration (>10 years). Costs associated with secondary care consultations seemed to be the primary factor in the association between HAQ-DI and total costs.

\begin{tabular}{|l|c|c|c|}
\hline \multicolumn{5}{|c|}{$\begin{array}{l}\text { Estimated HAQ-DI Coefficient ( } \\
\text { (Boot Unit) From Regression of Costs on the HAQ-DI } \\
\text { (Bootsapped SE, 95\% Cl, and P Value) }\end{array}$} \\
\hline Outcome & Estimate (SE) & $95 \%$ Cl & P Value \\
\hline Tests & $21.45(14.18)$ & $-7.93-47.5$ & 0.130 \\
\hline Accident and emergency & $15.67(5.46)$ & $6.46-28.89$ & 0.002 \\
\hline Primary care consultation & $69.98(24.32)$ & $20.97-115.90$ & 0.004 \\
\hline Secondary care consultation & $293.67(48.26)$ & $205.81-398.67$ & $<0.001$ \\
\hline Admitted care & $162.25(201.13)$ & $-132.82-707.29$ & 0.434 \\
\hline Total cost & $547.49(222.74)$ & $191.69-1,103.82$ & 0.004 \\
\hline
\end{tabular}

Conclusions: Models incorporating total healthcare costs were highly significant; this association appears to be driven mainly by secondary care consultation costs. Costs in this study were similar to previous studies in RA populations. A study limitation was that only direct medical costs were considered, which may underestimate the true burden of PsA on healthcare systems and the wider society. References:

[1] Lajas C, et al. Arthritis Rheum. 2003;49:64-70.

[2] Kobelt G, et al. Joint Bone Spine. 2008;75:408-15.

[3] Poole CD, et al. Rheumatology (Oxford). 2010;49:1949-56.

Disclosure of Interest: A. Maguire Grant/research support from: Cogentia Healthcare Consulting Ltd, UK, I. Handel Consultant for: Visible Analytics Limited, W. Tillett: None declared, F. Mughal Employee of: Celgene Ltd, J. Morris Grant/research support from: Celgene Ltd, N. Hawkins Grant/research support from: Celgene Ltd, C. Cavill Grant/research support from: Celgene Ltd, E. Korendowych Grant/research support from: Abbvie, Celgene and Pfizer, Consultant for: Janssen, Abbvie, Novartis, Pfizer and Celgene, Speakers bureau: Janssen, Abbvie, Novartis, Pfizer and Celgene, N. McHugh Grant/research support from: Celgene Ltd

DOI: 10.1136/annrheumdis-2017-eular.5332

\section{SAT0443 IDENTIFICATION OF PREDICTORS OF MINIMAL DISEASE ACTIVITY IN EARLY PSORIATIC ARTHRITIS}

A. Zabotti ${ }^{1}$, L. Idolazzi ${ }^{2}$, L. Quartuccio ${ }^{1}$, M. Sartori ${ }^{1}$, A. Fassio ${ }^{2}$, F. Zuliani ${ }^{1}$, D. Gatti ${ }^{2}$, M. Rossini ${ }^{2}$, S. De Vita ${ }^{1}$. ${ }^{1}$ Department of Medical and Biological Sciences, Rheumatology Clinic, "Santa Maria della Misericordia" University Hospital, Udine, Italy, Udine; ${ }^{2}$ Rheumatology Clinic, Aoui Verona Reumatologia, Verona, Italy

Background: Psoriatic arthritis (PsA) is a systemic inflammatory disease with articular and extra-articular features, the disease activity ranges from mild monooligoarthritis to destructive polyarthritis. Hence, establishing the prognosis of a patient with PsA is important to better define the treatment strategy. Furthermore, minimal disease activity (MDA) is a validated composite outcome measure since it correlates well with long-term outcomes (e.g. development of joint damage) ${ }^{1}$. Objectives: The aim of this study was to identify the baseline clinical variables associated with MDA at 12th month of follow up in two cohorts of early PsA Methods: Consecutive PsA patients, attending the outpatient Early Arthritis Clinic in Udine or Verona in the last two years, were assessed. All the included patients had: I) CASPAR score $\geq 2^{2}$ II) new diagnosis of PSA III) a complete clinical data and follow-up of at least 12 months. The GRAPPA recommendations on the management of PsA were followed. Statistical analysis included T- test, ANOVA and Pearson's test in order to find possible predictors of MDA.

Results: Eighty-one early PsA patients were included in the study. 47/81 (58.2\%) reached MDA at 12th month of follow-up; 68/81 (83.9\%) were in C-DMARDs while $11 / 81(13.6 \%)$ were in b-DMARDs. Two variables at baseline were selected comparing the groups based on achievement of MDA. These were: 1) LEI, which was significantly lower at baseline in patients reaching MDA (0.43 Vs 0.86 , $\mathrm{p}=0.001)$; and 2) a lower baseline CRP (1.2 mg/dl vs $2.8 \mathrm{mg} / \mathrm{dl}, \mathrm{p}=0.008)$. Of note, neither the baseline disease activity evaluated with DAPSA nor the time to referral were selected by statistical analysis.

Conclusions: Baseline lower LEI score and lower CRP were identified as clinical predictors of MDA after 12 months of treatment in PsA. Therefore, patients with a more active enthesitis or higher inflammation may have a less responsive disease. This may be relevant to select proper treatments at baseline, and indirectly confirms that enthesitis is a key therapeutic target in PsA.

\section{References:}

[1] Coates LC, Fransen J, Helliwell PS. Defining minimal disease activity in psoriatic arthritis: a proposed objective target for treatment. Ann Rheum Dis 2010; 69: 48-53.
[2] Coates LC, Conaghan PG, Emery P et al. Sensitivity and specificity of the classification of psoriatic arthritis criteria in early psoriatic arthritis. Arthritis Rheum 2012; 64: 3150-3155.

Disclosure of Interest: None declared

DOI: 10.1136/annrheumdis-2017-eular.4987

\section{SAT0444 DETECTION OF PSORIATIC ARTHRITIS AT EARLY ONSET: A MULTI-PROTEOMIC APPROACH TO DEVELOPING A NEW BLOOD TEST}

A.F. Mc Ardle $^{1}$, A. Szentpetery ${ }^{2}$, S. De Rook ${ }^{3}$, B. Hernandez ${ }^{1}$, O. FitzGerald ${ }^{4}$, S.R. Pennington ${ }^{1}$. ${ }^{1}$ School of Medicine and Medical Sciences, University College Dublin; ${ }^{2}$ Rheumatology, St. Vincents University Hospital, Dublin 4, Ireland: ${ }^{3}$ Wilhelmina Kinderziekenhuis, Hospital, Utrecht, Netherlands;

${ }^{4}$ Rheumatology, St. Vincents University Hospitla, Dublin 4, Ireland

Background: Psoriatic Arthritis (PSA) is an inflammatory arthritis (IA) frequently associated with psoriasis. Clinically, it is a complex heterogeneous disease and there are no diagnostic tests or criteria [1]. At first presentation, PsA may resemble other disease types - especially rheumatoid arthritis (RA). Making an accurate and early diagnosis is particularly important to ensure that individual patients receive effective and safe medication and so optimise long-term patient outcomes. Thus, it is widely acknowledged by physicians and patients alike that a new diagnostic test is needed to facilitate the early and specific diagnosis of PsA [2].

Objectives: To (i) identify and verify candidate biomarkers with the potential to segregate patients with PsA from those with RA; and (ii) explore the value of combining different proteomic discovery platforms.

Methods: Serum samples were obtained from a cohort of 64 patients (32 PsA and $32 \mathrm{RA}$ ) defined as early onset ( $<12$ months) and DMARD naïve. Individual baseline samples were analysed with label free LC-MS/MS $(n=64)$, the Luminex xMAP $(n=62)$ and an aptamer based platform called SOMAscan $(n=36)$. The random forest test was applied to each individual data set as well as to a combined-matched data set $(n=36)$. To verify MS data, a multiple reaction monitoring (MRM) assay was developed for 54 of the most discriminatory proteins to be applied to both pooled ( $P s A n=9, R A n=9$ ) and individual patient samples $(n=64)$.

Results: In this study, it was possible to quantify 387, 48 and 1129 proteins from LC-MS/MS, Luminex and SOMAscan analysis, respectively. Proteins with the ability to segregate PsA patients from those with RA were identified by random forest analysis; LC-MS/MS (AUC 0.94), Luminex (AUC 0.69) and SOMAscan (AUC 0.73). The application of the random forest model to the (i) combined data and (ii) MRM data set is part of ongoing work.

Conclusions: To date, statistical analysis revealed LC-MS/MS identified proteins were the most discriminatory. An MRM assay has been developed to the top 54 LC-MS/MS proteins and this assay has been applied to the discovery cohort (data analysis ongoing). The assay will next be applied to additional evaluation cohorts that include patients with spondyloarthritis and psoriasis. Discriminatory proteins verified here represent candidates for inclusion in a blood based multi-analyte test that could ultimately be used in the diagnosis of PsA.

\section{References:}

[1] Butt AQ, Mc Ardle A, Gibson DS, FitzGerald OF, Pennington SR. Psoriatic arthritis under a proteomic spotlight: application of novel technologies to advance diagnosis and management. Curr Rheumatology Reports 2015;17(5):35. doi: 1007/ss11926-015-0509-0.

[2] Mc Ardle, A. Butt AQ, Szentpetery, A. De Jager, Wilco. De Roock, Sytze. FitzGerald, O. Pennington, SR. Developing Clinically Relevant Biomarkers in Inflammatory Arthritis: A Multiplatform Approach for Serum Candidate Protein Discovery. Proteomics Clinical Applications, 2015. doi: 10.1002/prca. 201500046.

Disclosure of Interest: None declared

DOI: 10.1136/annrheumdis-2017-eular.5832

\section{SAT0445 SHORT-TERM EFFECTS OF SECUKINUMAB ON BONE TURNOVER MARKERS AND WNT SIGNALING ANTAGONISTS IN PATIENTS WITH PSORIATIC ARTHRITIS}

A. Fassio, L. Idolazzi, O. Viapiana, C. Benini, E. Vantaggiato, M. Rossini, D. Gatti. Rheumatology, Aoui Verona Reumatologia, Verona, Italy

Background: psoriatic arthritis (PSA) is a chronic inflammatory disease characterized also by increased levels of cells producing IL-17 [1], and these levels have been shown to correlate with measures of disease activity and structural damage and bone loss [2]. Secukinumab is a new monoclonal antibody licensed woth the treatment of PsA which selectively binds to and neutralizes interleukin-17 (IL-17). Currently, data about the effects on the activity of either bone-reabsorbing cells and bone-forming cells secondary to the inhibition of the IL-17 pathway are completely absent.

Objectives: the aim of our study was to explore the short-term effects of secukinumab on bone turnover markers (BTM) and Dkk-1 and sclerostin.

Methods: we enrolled 28 patients with PsA, classified with the CASPAR criteria and 43 healthy controls $(\mathrm{HC})$. For the PsA group DAS28 was recorded and serum samples were stored at baseline and then at the first, the third and the sixth month of therapy. Intact N-propeptide of type I collagen (PINP) and C-terminal 